Part of Journal of Research of the National Bureau of Standards, Volume 36, April 1946

\title{
NOTE ON THE DENSITY AND HEAT OF COMBUSTION OF BENZOIC ACID
}

\author{
By R. S. Jessup
}

\section{ABSTRACT}

The results of various determinations of the density of benzoic acid are summarized. The three most recent values are in reasonably good agreement with each other, but are higher by about 4.5 percent than the value most commonly referred to in the literature. The difference of 4.5 percent in density affects the reduction of weight in air to mass by an amount corresponding to 0.004 percent in mass, and in heat of combustion per gram mass.

The value $26428.4 \pm 2.6$ international joules per gram mass reported $[1]^{1}$ in 1942 for the heat of combustion of Bureau Standard Sample $39 \mathrm{f}$ of benzoic acid under the specified standard conditions of the bomb process was obtained from the experimental values of heat of combustion per gram weight in air, using the value 1.260 $\mathrm{g} / \mathrm{cm}^{3}$ for the density of benzoic acid at $25^{\circ} \mathrm{C}$ in making the reduction to mass. This value was derived from the value $1.266 \mathrm{~g} / \mathrm{cm}^{3}$ for the density at $15^{\circ} \mathrm{C}$ given in International Critical Tables [2], and the value 0.00053 per degree centigrade reported by E. R. Smith [3] for the coefficient of cubical expansion of benzoic acid in the range $15^{\circ}$ to $30^{\circ} \mathrm{C}$. The value of density given in ICT is apparently that reported by Lumsden [4] in 1905.

It has recently been noted that two other values have been obtained for the density of benzoic acid, namely, the value $1.322 \mathrm{~g} / \mathrm{cm}^{3}$ at $20^{\circ} \mathrm{C}$ reported by Steinmetz [5] in 1913, and the value $1.3211 \pm$ $0.0001 \mathrm{~g} / \mathrm{cm}^{3}$ at $23.3^{\circ} \mathrm{C}$ reported by Hendricks and Jefferson [6] in 1933. Steinmetz gave no information regarding his method of measurement or the accuracy of his result. Hendricks and Jefferson made measurements on single crystals grown from melts, by suspending the crystals in an aqueous salt solution, varying the concentration until the crystals just floated when the system was subjected to a centrifugal force of about 400 times gravity, and determining the density of the solution by means of a picnometer. The results were corrected for the effect of compressibility of solution and crystals. The individual results were not reported, but the probable error of the mean value was given as $\pm 0.0001 \mathrm{~g} / \mathrm{cm}^{3}$.

\footnotetext{
${ }_{1}$ Numbers in brackets indicate the literature references at the end of this paper.
} 
From the care with which the measurements of Hendricks and Jefferson were made, and from the agreement of their value with that of Steinmetz, it would seem that the older value of Lumsden is seriously in error. However, as no information was available regarding the reliability of the value reported by Steinmetz, and as it was not absolutely certain that the difference between the values of Lumsden and of Hendricks and Jefferson could be attributed entirely to error in Lumsden's data, an independent determination of the density of benzoic acid seemed desirable. Since an accuracy of 1 in the third decimal place is ample for the purpose of reducing weight in air to mass, it did not appear worth while to attempt to obtain higher accuracy than this.

To obtain samples of benzoic acid on which density determinations could be made, an attempt was made to grow single crystals from melts in the manner described by Hendricks and Jefferson. The product obtained was examined microscopically by C. P. Saylor, of the Chemistry Division of this Bureau, who reported that the samples were not single crystals, but were sufficiently compact and free from voids so that resasonably satisfactory density determinations could be made on them.

The density determinations were made by Mildred W. Jones, of the Weights and Measures Division of this Bureau, by the method of hydrostatic weighing in a saturated aqueous solution of benzoic acid. The density of this solution was determined by Mrs. Jones by means of a picnometer. Measurements on two samples of crystals prepared in separate experiments yielded the same value, namely, $1.316 \mathrm{~g} / \mathrm{cm}^{3}$ at $28^{\circ} \mathrm{C}$.

The results of the various determinations of the density of benzoic acid are given in table 1 . The reduction to $25^{\circ} \mathrm{C}$ was made by using for the coefficient of cubical expansion, $\gamma$, both the value 0.00040 reported by Schwab and Wichers [7] $]^{2}$ and the value 0.00067 that was obtained by recalculating the data of Smith [2] using the value $1.319 \mathrm{~g} / \mathrm{cm}^{3}$ at $25^{\circ}$ for the density of benzoic acid rather than the value $1.266 \mathrm{~g} / \mathrm{cm}^{3}$ at $15^{\circ} \mathrm{C}$ originally used by Smith. It will be seen from table 1 that although the two values of the coefficient of expansion differ considerably, the difference has only a relatively small effect on the values obtained for the density at $25^{\circ} \mathrm{C}$. It will also be seen from table 1 that the three most recent determinations are in reasonably satisfactory agreement with each other, whereas the value of Lumsden is lower by about 4.5 percent than the other three. It seems safe to conclude that the value reported by Lumsden is seriously in error. Any of the other values would be satisfactory for use in reducing weight in air to mass, as the value obtained for mass by using 1.3176 $\mathrm{g} / \mathrm{cm}^{3}$ for the density would differ by less than 2 parts in a million from that obtained with $1.3202 \mathrm{~g} / \mathrm{cm}^{3}$. In view of the fact that voids in the samples of benzoic acid would result in low values of density, and because of the care with which the measurements of Hendricks and

\footnotetext{
2 Schwab and Wichers calculated the density of solid benzoic acid at its melting point (by means of the Clausius-Clapeyron equation) from (1) their observed value of the pressure coefficient of the freezing temperature, (2) a value derived from data reported by Timmermans and Burriel [8] for the density of the liquid at the freezing temperature, and (3) the value given in International Critical Tables for the heat of fusion. The value $1.27 \mathrm{~g} / \mathrm{cm}^{3}$ obtained in this way, and the value of density at $23.3^{\circ} \mathrm{C}$ reported by Hendricks and Jefferson, were then used to calculate the mean coefficient of cubical expansion in the range from $23^{\circ}$ to $122^{\circ} \mathrm{C}$.
} 
Jefferson were made and the high precision of their results, their value is probably the most reliable one. It is therefore recommended that the value $1.320 \mathrm{~g} / \mathrm{cm}^{3}$ be used for the density of benzoic acid at $25^{\circ}$ $\mathrm{C}$ for the purpose of reducing weight in air to mass.

TABLE 1.-Values for the density of benzoic acid

\begin{tabular}{|c|c|c|c|}
\hline \multirow{2}{*}{ Observer } & \multirow{2}{*}{ Density reported } & \multicolumn{2}{|c|}{ Density at $25^{\circ} \mathrm{C}$} \\
\hline & & $\gamma=0.00040$ & $\gamma=0.00067$ \\
\hline $\begin{array}{l}\text { Lumsden (1905) } \\
\text { Steinmetz (1913) } \\
\text { Hendricks and Jefferson (1933) } \\
\text { Jones (this paper, 1945) }\end{array}$ & $\begin{array}{l}\quad \mathrm{g} / \mathrm{cm}^{3} \\
1.266\left(15^{\circ} \mathrm{C}\right) \\
1.322\left(20^{\circ} \mathrm{C}\right) \\
1.3211 \pm 0.0001\left(23.3^{\circ} \mathrm{C}\right) \\
1.316\left(28^{\circ} \mathrm{C}\right)\end{array}$ & \begin{tabular}{r|}
$\mathrm{g} / \mathrm{cm}^{3}$ \\
1.2610 \\
1.3194 \\
1.3202 \\
1.3176
\end{tabular} & $\begin{array}{rl}\mathrm{g} / \mathrm{cm} \mathrm{m}^{3} & 1.2577 \\
1.3176 \\
1.3196 \\
1.3186\end{array}$ \\
\hline
\end{tabular}

With $1.320 \mathrm{~g} / \mathrm{cm}^{3}$ as the value for the density, the value for the heat of combustion of Standard Sample 39f of benzoic acid becomes $26429.4 \pm 2.6$ international joules per gram mass when the sample is burned under the standard conditions [1] of the bomb process. It should perhaps be emphasized that when this standard sample of benzoic acid is used to calibrate a bomb calorimeter, no appreciable error would result from using the value originally reported [1] for the heat of combustion per gram mass of the sample, provided the value $1.260 \mathrm{~g} / \mathrm{cm}^{3}$ is used for the density of benzoic acid at $25^{\circ} \mathrm{C}$ in reducing weight in air to mass.

[1] R. S. Jessup, J. Research NBS 29, 247 (1942) RP1499.

[2] Int. Critical Tables 1, 208 (1926).

[3] E. R. Smith, BS J. Research 7,903 (1931) RP382.

[4] J. S. Lumsden, J. Chem. Soc. 87, 90 (1905).

[5] H. Steinmetz, Z. Krystallographie 53, 463 (1913).

[6] S. B. Hendricks and M. E. Jefferson, J. Opt. Soc. Am. 23, 299 (1933).

17] F. W. Schwab and E. Wichers, J. Research NBS 34, 333 (1945) RP1647.

[8] J. Timmermans and F. Burriel, Chimie \& industrie, Special No. pp. 196-7 (March 1931).

Washington, December 17, 1945. 